\title{
Rigidez escultórica e busca de temática clássica: o rigor formal na poesia de Francisca Júlia
}

\author{
Sculptural rigidity and demand for classic \\ themes: the formal accuracy in the poetry of \\ Francisca Júlia
}

João Vicente ${ }^{1}$

\author{
O rosto não encara indiferente, \\ Nem a traidora mão cândida aperta; \\ Das mentiras da vida se liberta \\ E entra no mundo que jamais não mente. \\ (Machado de Assis - "A flor do embiruçu”)
}

\section{Resumo}

Este estudo visa compreender o rigor formal e as relações plásticas na obra da poeta Francisca Júlia, considerada por muitos autores como "Musa impassível", uma vez que seus poemas correspondiam ao auge da impassibilidade parnasiana. Procurou-se verificar em seus poemas a presença do lirismo e os limites do descritivismo plástico que deixaram também ver o fazer poético marcado pelo eu lírico, retomando elementos românticos e absorvendo sugestões simbolistas. Foram analisados poemas dos dois livros publicados pela autora: Mármores (1895) e Esphinges (1921). Os elementos formais e de conteúdo foram estudados visando incrementar o entendimento não só da obra de Francisca Júlia, mas também o do Parnasianismo como movimento literário de grande repercussão no Brasil. Conclui-se que, ainda que fiel seguidora da escola parnasiana, a poeta apresenta em suas obras elementos de ruptura e continuidade com tendências da poesia lírica local e universal, eixo constitutivo do sistema literário brasileiro.

Palavras-chave: Poesia Parnasiana. Francisca Júlia. Lirismo. Tendências literárias. Sistema literário.

\begin{abstract}
This research studies the work of the Parnassian poet Francisca Júlia, considered by many authors as "Impassive Muse", since his poems correspond to the pinnacle of the Parnassian impassivity. The lyricism and limits of plastic descriptivism were examined in her poems, also the making poetry marked by lyrical, romantic elements and absorbing symbolists suggestions. For this study, we analyzed two books of poems published by the author: Mármores (1895) and Esphinges (1921). The formal elements and content were studied in order to increase the understanding not only of the work of Francisca Júlia, but also the Parnassianism as a literary movement of great repercussion in Brazil. We conclude that, although faithful follower of the Parnassian style, the poet presents in his works elements of rupture and continuity with trends in poetry local and universal, axis constitutive of Brazilian literary system.
\end{abstract}

Keywords: Parnassian poetry. Francisca Júlia. Lyricism. Literary trends. Literary system. 


\section{Francisca Júlia: musa impassível}

Trata-se de poeta incluída por Alfredo Bosi (1994, p. 229) no grupo de poetas menores do Parnasianismo, mas que mereceriam atenção por nem sempre terem se limitado a repetir os modelos consagrados. Os desvios ao modelo são bastante interessantes e não ocorrem apenas nos poemas de cunho simbolista produzidos por Francisca Júlia. Para Alfredo Bosi, tendo ela vindo após a consagração dos mestres, logo alcançaria o nível daqueles, tal a "fidelidade e mesmo rigidez, com que praticava os princípios da escola". No entender de Péricles Eugênio da Silva Ramos, talvez só ela tenha atingido sistematicamente as condições de impassibilidade que o Parnasianismo em tese reclamava.

Sua obra poética definitiva, anunciada na publicação de Esphinges, em 1903, se chamaria Místicas, mas jamais foi concluída. Francisca Júlia, em entrevista acerca da publicação de Esphinges, anunciou a elaboração de um curso de literatura para o uso dos ginasianos de São Paulo (CAMARGOS, 2007, p. 35). Na mesma entrevista, fala na publicação de "Versos Áureos", com poemas baseados na moral de Pitágoras. Entretanto, sua obra mais bem acabada é aquela que se aproxima das esculturas de mármores bem acabadas e não os poemas que se inspiram diretamente em perspectivas moralistas; ainda que haja sempre algo de moral no mais impassível poema parnasiano.

Francisca Júlia conheceu grande sucesso durante sua vida. Mármores causou sensação nas rodas culturais de São Paulo e do Rio de Janeiro (CAMARGOS, 2007, p. 27). Provas de sua celebridade à época são as capas de A Cigarra (22 de agosto de 1895) e A Pauliceia (15 de agosto de 1896), que a traziam estampada como desenho ou retrato. Fez parte de comitês de julgamento de concursos de poemas; foi proclamada membro-efetivo do Comitê Central Brasileiro da Società Internazzionale Elleno-Latina de Roma, pelo poeta Péthion de Villar; fez conferências literárias, dentre outras formalidades de academia. No entanto, em entrevista ao Pirralho, sobre a Academia de Letras, afirmou "Não creio em academias, a arte não se faz por associação" (São Paulo Intelectual: FJ fala ao Pirralho (25/10/1913) apud MARTINS, 2008, p. 436). Em 1896, período que LÔBO (1994, p. 11) classifica de "fecundo e exuberante", foi fundada a Academia Brasileira de Letras; a forma de arte predominante era o Parnasianismo. Estiveram entre os fundadores os três principais autores dessa escola: Olavo Bilac, Alberto de
Oliveira e Raimundo Correia. Também após sua morte, em 1920, Francisca Júlia foi considerada uma "personalidade representativa" pelo crítico americano Isaac Goldberg (MARTINS, 2008, p. 488), que dedicou a ela um capítulo em Brazilian Literature, de 1922. Sobre Francisca Júlia, Machado de Assis em sua crônica n'A semana de 14 de julho de 1895 declarava:

Francisca Júlia da Silva, a patrícia nossa, se é certo o que nos conta João Ribeiro, no excelente prefácio dos Mármores, já escrevia versos aos quatorze anos. Bem podia dizer, pelo estilo de Bernardim: "Menina e moça me levaram da casa de meus pais para longes terras"... Essas terras são as da pura mitologia, as de Vênus talhada em mármore, as terras dos castelos medievais, para cantar diante deles e delas impassivelmente. "Musa Impassível", que é o título do último soneto do livro, melhor que tudo pinta esta moça insensível e fria. Essa impassibilidade será a própria natureza da poetisa, ou uma impressão literária? Eis o que nos dirá aos vinte e cinco anos ou aos trinta. Não nos sairá jamais uma das choramingas de outro tempo; mas aquele soneto da p. 74, em que "a alma vive e a dor exulta, ambas unidas", mostra que há nela uma corda de simpatia e outra de filosofia.

Uma das últimas homenagens à autora, e a mais bela, é a escultura Musa Impassível, de Victor Brecheret, possivelmente o maior escultor brasileiro, foi feita sob encomenda do Estado de São Paulo. A obra de mais de três toneladas de mármore Carrara, uma figura feminina de quase três metros de altura, foi esculpida na França, e ornamentava o túmulo da poeta até 2006 quando foi transferida para a Pinacoteca de São Paulo. Exposta às intempéries tropicais poderia exibir fraturas, tal qual aconteceu com sua inspiradora.

\section{O movimento na obra impassível}

À primeira vista, a obra poética de Francisca Júlia é tida como puramente parnasiana e analisada com as prerrogativas da escola, ou seja, será considerada hermética e encerrada em si mesma. Nessa pesquisa buscamos discutir, inicialmente, a característica parnasiana mais marcante da autora: a impassibilidade, buscando tensionar esse traço para além da constatação de sua existência na obra de Francisca Júlia. Abordamos a presença de outros dois elementos bastante ligados à estética parnasiana na obra de Francisca Júlia: a aproximação com a escultura e a temática clássica. Um problema central que perpassa o estudo da obra são as diferentes tendências da tradição 
literária que atravessam a poesia da autora, entre a musicalidade do verso e a plasticidade dos quadros temáticos de seus poemas, procurando articulá-las à possível relação entre lirismo e reificação. Para tanto, apresentamos sonetos de Francisca Júlia, buscando realizar uma análise progressiva, de acordo com a complexidade do tema de alguns deles frente à discussão proposta, tentando também imprimir uma lógica sucessiva entre eles, ordenada não pelo critério cronológico, mas pela problematização proposta.

Não é raro encontrar a ideia de arte pela arte associada ao Parnasianismo. Na visão geral, esse conceito se associa a uma relação distante da vida social e pouco reflexiva sobre essa. Para o aparecimento e fixação dessa doutrina, foram fundamentais autores como Baudelaire, Flaubert e, especialmente para o Parnasianismo, Leconte de Lisle e Théophile Gautier. Esse último pregava em seus textos uma "poesia plástica e impassível, o culto da beleza e da perfeição técnica, a independência e a nobreza da arte" (LÔBO, 1994, p. 29). Esses são elementos a serem estudados, mas é preciso ir além das camadas mais ostensivas. Como afirma Antonio Candido (2005, p. 14):

O estudioso da literatura não pode dispensar o conhecimento adequado dos aspectos externos, porque não lhe basta, como leitor comum e mesmo ao amador do bom gosto, sentir e gostar; sua tarefa não se perfaz sem os conhecimentos obtidos pela erudição literária. Ora, tais conhecimentos principiam pelos elementos mais humildes da obra (o seu corpo ou configuração material), que podem, [...] assumir grande importância.

Ou ainda como afirma Benjamin (2011, p. 29):

[...] por mais bela que seja uma casa, ela tem antes de tudo - e antes que nos detenhamos em sua beleza - tantos metros de altura e tantos de comprimento. Assim também é a literatura, que reproduz a substância mais difícil de avaliar, antes de tudo um enchimento de linhas, e o arquiteto literário cujo simples nome não promete lucros tem de vender a qualquer preço.

A perfeição dos versos, em termos de estrutura e linguagem dos parnasianos nem sempre foi bem recebida. O sucesso dos poetas e do momento literário brasileiro é bastante relativo, já o que o público leitor passava ao longe de contemplar as massas do país. A eleição das formas rígidas e impessoais foi uma escolha que "petrificou a expressão" sendo claro seu caráter aristocrático:

A busca da perfeição pela correção gramatical, a volta aos clássicos e o rebuscamento marcam uma atitude de tipo aristocrático e constituem um traço saliente da fase que vai dos anos de 1880 até a altura de 1920, correspondendo a um desejo generalizado de elegância ligado à modernização urbana do país, sobretudo sua capital, Rio de Janeiro. Do ponto de vista da literatura, foi uma barreira que petrificou a expressão, criando um hiato largo entre a língua falada e a língua escrita, além de favorecer o artificialismo que satisfaz as elites, porque marca distância em relação ao povo; e pode satisfazer a este, parecendo admiti-lo em terreno reservado. Essa cultura acadêmica, geralmente sancionada pelos poderes, teve a utilidade de estimular, por reação, o surto transformador do Modernismo, a partir de 1922. (CANDIDO, 2004, p. 78-79)

Segundo Danilo Lôbo (1994, p. 116), o descritivismo escultural do Parnasianismo tem sua base na tentativa de impessoalidade do autor e impassibilidade da obra. Ainda de acordo com esse autor, essas características são contrárias à lírica e apenas podem ser conseguidas "graças a um esforço racional".

$\mathrm{O}$ anseio pela plasticidade é visível em diversas obras de Francisca Júlia, por exemplo, em "Desejo Inútil” onde podemos ler versos como: "Qualquer cousa afinal de bello escolher devo/Para um verso plasmar no esforço da obra-prima”. Os dois primeiros versos desse soneto são bastante sintomáticos da estética, escolher "qualquer coisa" para buscar a "obra-prima”, o que soa contraditório para uma arte preocupada com seus conteúdos e efeitos. Francisca Júlia quer apenas educar para o belo estético, não para conteúdos. Peca assim, tanto quanto os artistas que colocam os preceitos morais e didáticos à frente da forma. Mais adiante neste mesmo soneto, o "eu” lírico irá considerar: "Tudo o que diga e exprima/Perde, ao moldar-se em verso, o seu próprio relevo". Tais versos mostram que a poeta tinha clareza quanto ao fato de que a matéria-prima utilizada pela arte vem do mundo e que, ao ser representada artisticamente, não é mais o mundo, não tem mais seu relevo, mas sim um relevo próprio do objeto artístico, que não pertence mais ao mundo cotidiano, que se cristaliza em um bloco de mármore, esculpido como ornato de baixo-relevo. Conforme discute Bastos (2012, p. 16-17):

A relação dos sujeitos humanos com os objetos é na verdade relação entre homens e, como relação fetichista, é sempre fantasmagórica: o objeto parece autônomo e capaz de impor suas condições aos homens. O fato da aparente autonomia do objeto é já, por si mesmo, uma ameaça - e, neste cão, já cumprida. O objeto, que o homem produz e a que empresta uma destinação, se "autonomiza". É vampiresco, porque suga a humanidade daquele que o produziu. 
Há, no Parnasianismo uma visível aproximação com as artes plásticas pela utilização de vocabulário desse campo semântico, como esculpir, construir, cinzelar, a citação de diversos materiais, cores, enfim, um jargão dessa área da arte em geral. A crítica da época também não se eximiu em utilizar esse léxico em suas análises, que na maior parte das vezes se restringiu a observar a transcendência da obra.

É preciso pensar não apenas que o Parnasianismo nas Letras associa-se às artes plásticas clássicas, especialmente esculturas, mas também à visão plástica da época que é de tendência descritiva. $\mathrm{O}$ contexto histórico-cultural é característico da influência da técnica, da reprodução, o uso de equipamentos. Os sonetos "moldados" no Parnasianismo talvez apresentem certa "seriação" como a das gravuras e fotografias. Também são frequentes sonetos que ressurgem reformulados, corrigidos, aparados; talvez sejam exemplos disso os dois "Musa Impassível”. Isso fica visível na repetição de temas e de modelos criticada por Mário de Andrade: "agora está muito em moda dizer que os poetas não copiam... inspiram-se” (1921, p. 261).

A utilização de esculturas é recorrente na obra de Francisca Júlia, são pelo menos duas "Musa Impassível”, uma "Venus" e uma "Amphitrite" além dos títulos dos dois volumes publicados Mármores e Esphinges, um remetendo ao material e outro à obra já acabada. Considerando-se que o segundo é uma elaboração mais refinada do primeiro as títulos remetem ao próprio trabalho da poeta.

\section{"Dança de Centauras": escultura em movimento}

No momento, interessa ler o poema "Dança de Centauras", tido por Mário de Andrade como "duma beleza sublime” e que é, no mínimo, um diálogo com “Fuite de Centaures", "Centaures et Lapithes" e também "La Centauresse". Todos são de autoria de José Maria Heredia, poeta cubano e radicado na França, que, diriam os mais rigorosos, Francisca Júlia buscou imitar, e outros considerariam seu maior inspirador, nesse caso, tudo depende do ponto de vista do crítico. A respeito da reorganização da matéria no ato poético Bastos (1987, p. 31) pondera:

Da matéria, indeterminada e desorganizada, pode o poietés, o poeta, artista, mediante a sua inteligência criadora, produzir a obra de arte, da mesma maneira que a inteligência divina organiza o Universo. Quanto à mimesis, a imitação da Natureza pelo artista [...] é uma recriação, numa outra existência - a obra de arte -, das essências universais. A imitação, a mimeses, efetuada pela arte, consiste, inclusive, num aprimoramento da Realidade, à medida que o artista, imitando o aspecto essencial e universal das coisas, purifica a Natureza da materialidade nela contida.

Assim como os dois sonetos franceses, a "Dança de Centauras", de Francisca Júlia, trata de uma fuga das centauras após perceberem a aproximação de Hércules. Leiamos o soneto a fim de começar uma análise de sua forma e conteúdo temático clássico, porém, nesse caso, de segunda mão, já que a inspiração parece vir mais da França que da Grécia. Talvez a matéria aqui utilizada para a poesia seja a própria poesia parnasiana de Heredia. Segundo Mario de Andrade (1921), nos sonetos caracteristicamente parnasianos havia quadras, tercetos e versos iguais e mesmo preferíveis, pela sonoridade da nossa língua, aos melhores do congênere parisiense.

\section{Dança de Centauras}

$$
\text { (Esphinges) }
$$

A Coelho Netto.

Patas dianteiras no ar, boccas livres dos freios, Nuas, em grita, em ludo, entrecruzando as lanças,

Eil-as, garbosas vêm, na evolução das danças Rudes, pompeando á luz a brancura dos seios.

A noite escuta, fulge o luar, gemem as franças; Mil centauras a rir, em lutas e torneios, Galopam livres, vão e vêm, os peitos cheios De ar, o cabello solto ao léo das auras mansas.

Empallidece o luar, a noite cae, madruga... A dança hippica pára e logo atroa o espaço O galope infernal das centauras em fuga:

É que, longe, ao clarão do luar que empallidece, Enorme, acesso o olhar, bravo, do heróico braço Pendente a clava argiva, Hercules apparece...

É interessante notar que a beleza plástica desse soneto é reconhecida tanto por Mário de Andrade, quanto por Coelho Neto. Esse último, a quem Francisca Júlia dedicou “Dança de Centauras", considerou em 17 de abril de 1902 em O Estado de São Paulo (apud CAMARGOS, 2007, p. 53):

Não é uma cena morta, posto que seja trabalhada em mármore - tem a vida arrojada do Discóbolo e tem a beleza da Ártemis. A forma, tão polida em todos os seus contornos, não delicia simplesmente pela beleza externa - contém uma ideia que inspiraria ao pintor e ao músico". E conclui "Não basta ter a ideia de um tripudio quadrupedante de centauras ao luar, é mister saber representar esse sonho detalhando minuciosamente toda a ficção para que se sinta, como se sente, a ilusão poética. 
Já Mário de Andrade (1921, p. 261) diz, a respeito desse soneto, que há nele, "além da Beleza, a comoção, o símbolo, a verdade dos arrependimentos, dos remorsos e das covardias; sente-se lhe no interior, espumejando em cachões larguíssimos, toda uma história de humanidade castigada pelo amor". Assim vemos que esse crítico, apesar de aparentemente se voltar contra os mestres do passado, soube também reconhecer o valor deles. De acordo com Duarte (1997, p. 100):

apesar dos reparos que faz, ele não foi tão contundente com a poesia, como com os outros poetas. Senão, vejamos. O crítico afirma, por um lado, que ela é dotada de "pouca inspiração", que se ocupou muito em fotografar poetas e heróis antigos em versos perfeitos e ainda, que tem belos poemas, mas que, infelizmente, estão comprometidos por um ou outro verso mal construído.

A arte clássica é eminentemente simétrica e, na área da escultura, fundamentalmente realista. A simetria foi um primeiro conceito plástico que observamos na organização dos poemas e do livro Mármores, por exemplo, com a abertura e encerramento com um poema de mesmo título e tema, o nosso "Musa Impassível". Em "Dança de Centauras", apesar de termos como assunto poético uma cena de fuga de monstros mitológicos, tudo se nos apresenta de maneira bastante organizada, didática. O quadro inicial é construído com uma visão nítida, em branco e iluminada pelo luar das Centauras que livres e felizes galopam em vai e vem. Em seguida, com a aproximação do dia e a chegada de Hércules, elas devem fugir.

É interessante pensar que o soneto, forma de poema privilegiada pela autora em estudo, era desconhecido na Antiguidade clássica grega e latina, sendo um produto da alta Idade Média (AMARAL, 1993, p. 65). Portanto, a influência para a estrutura se dá apenas pela importação da forma francesa, nada há do metro grego. Os monstros mitológicos e o herói são ornatos, decalques sobre um "vaso" bem brasileiro. Apesar do distanciamento e da forma relativamente artificial do soneto em relação à Antiguidade Clássica, é patente observar que a métrica grega possuía feições bastante distintas da de nossas línguas modernas. Além disso, não podemos resumir a forma soneto como algo que surge de maneira espontânea e se fixa. Ele teve um processo de desenvolvimento, e foi largamente difundido, especialmente nas línguas latinas, ou seja, é produto de processo de maturação estética de vários poetas, em geral europeus. Cabe neste trabalho, discutir mais os efeitos de significado do uso dessa forma que o detalhamento do surgimento e evolução do soneto. A formulação de Hess (2009, p. 4) aqui nos é bastante esclarecedora sobre essa proposição. Essa autora a considera a existência de uma escola parnasiana como "questão polêmica para a França e pacífica para o Brasil", pois no primeiro país verificou-se uma marcha rápida de evolução da lírica, partindo "para formas que superavam o descritivismo petrificador em que se guardava a obra dos poucos poetas franceses que podem ser chamados parnasianos" enquanto no Brasil houve bastante resistência para sua permanência.

De acordo com Mário de Andrade, Francisca Júlia fotografou todos "os heróis do mundo antigo nos versos perfeitos e bem urdidos", mas não o teria feito por meio da "fantasmagoria movediça e comovente das brumas seculares", e sim sob o sol claro e amigo, demasiadamente perto como a lente de uma câmara: "Não vivos, infelizes, palpitantes, mas estarrecidos, gelados, marmorizados num grande friso mais longo do que o purgatório dantesco". Por outro lado, o que soa como um julgamento bastante negativo é amenizado pelo crítico: "no entanto, não depõe contra a autora que, de fato, pretendeu passar a sensação de quem captou a realidade para imobilizá-la em uma visão a que as palavras conferem substância”.

Talvez, como afirma Valarini (2007), o Parnasianismo tenha interrompido o desenvolvimento de uma forma poética autêntica, ao preconizar versos presos a estruturas formais e objetivas, que não davam vazão ao sentimento, à emoção e, sobretudo, ao engajamento social, que os parnasianos "negavam" ardentemente. A autenticidade a qual discute Valarini (2007) pode ser vista também como uma certa espontaneidade que esperamos do poeta brasileiro, do escritor brasileiro, do artista enfim. Com o espírito romântico que ainda permanece, era de se esperar de nossos poetas a busca pela forma e conteúdos autenticamente "nossos". Se essa espontaneidade não aparece na forma soneto, transplantada em terras brasileiras depois de desenvolvida na Europa, ela surge em nos meandros de suas estruturas dando a ver a "cor local". Tal processo fica mais claro quando vemos no soneto "Dança de Centauras" a possibilidade de uma leitura como a tematização da liberdade e de sua restrição imposta pela chegada à cena daquele que representa a força da masculinidade, e, no caso do Brasil, talvez com a devida modalização, essa força não possa ser desassociada de uma forma de produção e organização da vida que se impõe sobre um país novo e de gentes tão distintas: a universalização do modo produção capitalista. 
O sistema capitalista mundializado, se associado a sua força hercúlea sobe o mundo, dispersa as forças anteriores que não cabem mais ou não se submetem a sua dominação. Os homens "tiveram que sacrificar o melhor da sua qualidade de homens para levar a cabo os milagres da civilização que enchem a cidade", considera LEFEBVRE, analisando a situação dos trabalhadores londrinos na revolução industrial sabemos que em outro chão histórico, a situação brasileira, analisada a fundo, talvez só seja diferente pelo fato de que, aqui, os benefícios contraditórios da civilização foram menos hercúleos que os malefícios. Era tempo de produzir, produzir inclusive poesia, literatura nacional de um país sem cultura letrada efetivamente socializada, e “a produção tudo abarca e nada exclui do que é humano. $\mathrm{O}$ mental, o intelectual, o que passa por "espiritual" são produtos como todo o resto" (LEFEBVRE ,1972, p. 46).

Konder (2005, p. 21), refletindo sobre a leitura da poesia, considera:

\begin{abstract}
A poesia é, de fato, um gênero árduo, que exige muito do poeta, mas também exige muito do leitor: exige que o leitor se esforce para 'receber' o poeta (o Outro) de maneira a poder assimilar o que ele lhe traz, 'traduzindo-o' ou 'recriando-o' na sua linguagem pessoal. Quer dizer: a poesia exige do leitor que ele libere ou crie e desenvolva a parte que precisa existir nele.
\end{abstract}

Por estarmos em pleno acordo com tal reflexão, uma questão surge imperiosa, como poderiam os leitores do Brasil de 1895 receber poemas como "Dança de Centauras" e o incensar? Talvez a imaginação a ser liberada não buscasse entender o significado da fuga de seres tão felizes quanto às centauras dos dois primeiros quartetos, mas de julgar como relevante a chegada de um ser "organizador" a essas paragens, um ser hercúleo que limitasse a algazarra, que promovesse a "ordem" pela ameaça que se anunciava com a sua chegada.

Há, no poema, uma descrição com traço narrativo e nenhum emprego de primeira pessoa. O quadro desenhado tem um movimento muito lento que se pode notar ao longo do soneto, apesar de abarcar um período muito curto e rápido: de uma noite até o momento em que amanhece, que "madruga". A estrutura de narrativa também se faz na pontuação, antes de passarmos ao último terceto, ou seja, à conclusão do poema, aparecem dois pontos que preparam o grande desfecho. Desfecho esse que é apenas a ameaça da chegada de Hércules que aparece ao longe.

O centauro é um ser mitológico que habitaria a Terra antes da humanidade, de rosto e torso de homem possuía pernas e garupa de cavalo, "uma espécie de monstro. a imagem do homem fundido com a besta em que monta” (MARTÍNEZ, 2009, p. 10), "por meio de figuras como a do centauro é possível buscar aceder ao âmbito do mito" (MARTÍNEZ, 2009, p. 11). Como ressalta Piras (2005), seguir a trilha do mito na literatura significa investigar como ela foi adornada com a linguagem, como nela floresceram as imagens, mas "isso também significa refazer a história das ideias”. Em uma pesquisa mais superficial não encontramos referência ao seu feminino, à centaura, em textos sobre a Antiguidade clássica. As referências são relativas apenas aos poemas de José Heredia como já citamos. No poema "No campo", que veremos a seguir, também teremos uma versão feminina, agora do pastor. Por outro lado, Hércules seria a um semideus, filho de Zeus e uma mortal, que tem como missão cumprir doze trabalhos. De uma maneira simplificadora, podemos dizer que são tarefas direcionadas a tornar o mundo seguro para a humanidade. Os seres primitivos da Terra já não têm seu lugar assegurado no mundo olímpico e tem em essa nova figura masculina que se impõe, inclusive sem critérios éticos, para instaurar a ordem olímpica. Uma questão referente ao diálogo com a própria tradição literária de Francisca Júlia, enquanto inscrita na literatura ocidental via Parnasianismo brasileiro, nesse poema, é que a autora usa o nome latinizado do herói, que em grego seria Heracles.

\section{“No campo" uma pintura de inspiração clássica}

Em outro soneto de Francisca Júlia, há também a imagem de outro ser masculino e de comportamento hegemônico em relação a uma coletividade. Trata-se de "No campo", soneto de rimas entrecruzadas e de tema muito simplório, a descrição de uma paisagem rural fazendo lembrar o bucolismo árcade, porém ao invés de um pastor aparece uma pastora, uma "campônia":

\section{No campo}

(Mármores)

A Max Fleiuss.

Olhos chorosos sob as negras sobrancelhas, Costas abaixo solta a negra trança basta, A camponia vae guiando, a picadinhas d'hasta, Um rebanho gentil de candidas ovelhas. Uma junta de bois morosa, em meio à vasta Nava, arrastando vae umas charrúas velhas... E escutando o raspar monotomo das rélhas, Queda-se na planicie um grande boi, que pasta... 
E some-se o rebanho. Uma sombra fluctuante Paira sobre a extensão da planicie, distante... $\mathrm{Na}$ espessura a camponia esconde-se depois. E, ao longe, sob o céo, como uma prece extranha Que desperta a mudez do campo e da montanha, Chora no ar o mugir dos fatigados bois.

Assim como em "Dança de Centauras", em que se vê Hércules que aparece em meio às Centauras alegres e livres, neste poema temos "um grande boi, que pasta" e um rebanho de brancas ovelhas conduzidas pela pastora. Nesse segundo poema, a relação que vemos é de uma espécie de progressão temática em relação ao primeiro. Não é mais necessário ameaçar a coletividade, pois ela se mostra dócil e obediente, basta quedar-se sobre a planície. A cena descrita parece ser muito mais palpável que a anterior, ainda que ovelhas sejam muito mais frequentes na Europa que no Brasil, mas os personagens descritos são animais reais, biologicamente falando. Enquanto em Centauras temos monstros de torso humano e garupa animal. O segundo tem um ar muito mais vazio, cheio de uma "sombra flutuante que paira sobre a extensão da planície". A "artificialização do espaço poético" (CANDIDO, 2002, p. 66) soa ainda maior nesse segundo soneto do que no primeiro.

Nesta análise, em momento algum, procuramos "descobrir" as intenções da autora, mas sim correlacionar seus versos ao momento social do Brasil, já que partimos da prerrogativa de que a arte internaliza a estrutura social como matéria-prima. O poema "No campo" chega a ser inocente se comparado tematicamente a "Dança das Centauras". Porém ambos carregam uma ideia de paralisação do tempo, descrevem uma cena que seria dinâmica, porém em processo que nos leva a enxergá-la como uma escultura ou um quadro.

\section{Conclusões}

Em momentos como os analisados acima, pode-se dizer que e poesia de Francisca Júlia trata e mesmo questiona o fazer artístico e os limites da representação. Em termos temáticos, tal questão é bastante forte no poema "Desejo Inútil". A própria ideia de transfiguração nos é apresentada "Tudo que diga ou exprima perde, ao moldar-se em verso, o seu próprio relevo". Perde-se o relevo, porém pode-se perceber que permanece na obra de arte, no poema. Ao falar do processo de produção do poema, pode-se ouvir o "rumor" da quebra do mármore, isto é, para além do poema burilado com rigor há certo descon- forto, certo descompasso. Provavelmente, um descompasso entre vida social e forma estética.

Os poemas analisados mostram que a literatura ao transfigurar em objeto estético elementos da vida real não pode, por mais que tenha essa intenção, fugir completamente de sua realidade social. A matéria-prima, ainda que fortemente alterada e cristalizada em forma estética, mantém nesta elementos que podem objetivamente falar da composição social e estruturação da realidade em que a obra e o leitor se situam. O movimento Parnasiano no Brasil foi e continuou sendo forte por um tempo considerável, é necessário aprofundar os estudos nessa área, buscando ressignificar sincronicamente esta escola literária, buscando descobrir se realmente a "imaginação ficou presa no limite da rima”. Haveria, ainda assim, um esforço de se exprimir o novo sem abandonar o velho? Seria possível considerar, como fez Antonio Candido (2004, p.15) a respeito dos críticos nacionalistas, que houve falha em ver diminuição e subserviência no uso das formas clássicas e da mitologia Greco-latina?

Considerando-se o percurso de produção poética de Francisca Júlia verificamos que o principal modo de divulgação de seus poemas foi a veiculação em jornais da época. Dessa forma, seus livros Mármores e Esphinges representam compilações e não uma obra em termos de unicidade. De fato, o segundo contém a maioria dos poemas do primeiro, com poucas subtrações e alguns poemas novos, a maioria já publicada isoladamente. Essa informação, somada à preferência pelo soneto, contribui para demonstrar a importância do individual na obra em estudo, visto que a fragmentação é notada tanto em termos de extensão de cada obra, como na falta de conexão, mais ostensiva, de cada peça em relação às demais dentro de cada livro.

O sucesso de público e crítica, seja dos sonetos em periódicos, seja das compilações, é fato constatado quando pesquisamos a literatura da época. No entanto, sabemos que o público leitor de então era reduzido e havia uma intenção de refinamento, de "ourivezação" da literatura, visando mantê-la em seu local de privilégio, tanto do ponto de vista da produção quanto da leitura. Apesar de atualmente ser visto como a forma do atraso em poesia em si, os sonetos parnasianos no Brasil ganharam seu destaque em um contexto de grande modernização dos pensamentos, da vida, das formas. De certa forma, podemos dizer que tal momento é também concomitante a uma padronização, uma certa uniformização da produção, que se pode 
ver com nitidez na poesia parnasiana no Brasil produzida. Assim, "a discussão em torno da estética parnasiana muito provavelmente não poderia se dar sem que se passasse primeiro pela questão relativa ao significado que a forma chamada fixa carrega consigo e ao ajuste dessa forma fixa à matéria local brasileira" (HESS, 2009, p.1). Se o contexto de surgimento do Parnasianismo e sua visão cientificista da modernidade podem ser associados a um momento em que "os homens renunciaram ao sentido e substituíram o conceito pela fórmula, a causa pela regra e pela probabilidade "(ADORNO; HORKHEIMER, 1985, p. 21); por outro lado, os elementos que convencionalmente caracterizam o Parnasianismo foram importantes para reafirmar, frente a esse mundo de inversões, certa autonomia da arte e também de seus autores, como trabalhadores da literatura. A quebra da promessa de impassibilidade e culto da forma, feita por Francisca Júlia, que demonstrou desde suas primeiras produções tendências românticas, simbolistas e decadentistas, também pode ser vista, metonicamente, em graus diversos é claro, como praxe nos poetas parnasianos brasileiros. Fica-nos claro então que a questão da aclimatação da forma foi forte, de tal forma que não permitiu os versos puramente descritivistas que esperavam os mestres da escola francesa. No Brasil, as formas deram também voz a um estilo mais romântico e que se mostrou mais maleável, chegando a flertar com a musicalidade do Simbolismo.

\section{Referências}

ADORNO, Theodor W.; HORKHEIMER, Max. Dialética do esclarecimento: fragmentos filosóficos. Tradução de Guido Antonio de Almeida. Rio de Janeiro: J. Zahar Editor, 1985.

AMARAL, Adilson do. Introdução à arte de fazer versos. (Trova, Sextilha, Soneto). Brasília: Meio Tom, 1993.

ANDRADE, Mario de. Mestres do passado. In: BRITO, Mário da Silva. História do modernismo brasileiro: I. Rio de Janeiro: Civilização Brasileira, 1964. p. 253-254.

ASSIS, Machado de. A nova geração. Revista Brasileira, Rio de Janeiro, volume II p. 81. 1879.

ASSIS, Machado de. Crônica de 14 de julho de 1895. A semana, Gazeta de Notícias. Rio de Janeiro. p. 74. 1895.

BASTOS, Fernando. As artes da ameaça: ensaios sobre literatura e crise. São Paulo: Outras Expressões, 2012.
BASTOS, Fernando. Panorama das ideias estéticas no ocidente: de Platão a Kant. Brasília: Universidade de Brasília, 1987.

BENJAMIN, Walter. Charles Baudelaire: um lírico no auge do capitalismo. Obras escolhidas III. São Paulo: Brasiliense, 2011.

CAMARGOS, Márcia. Musa impassível: a poetisa Francisca Júlia no cinzel de Victor Brecheret. São Paulo: Imprensa Oficial do Estado de São Paulo, 2007.

CANDIDO, Antonio. Iniciação à literatura brasileira. 4. ed. Rio de Janeiro: Ouro Sobre Azul, 2004.

CANDIDO, Antonio. Na sala de aula: caderno de análise literária. São Paulo: Ática, 2002.

CANDIDO, Antonio. Noções de análise histórico-literária. São Paulo: Associação Editorial Humanitas, 2005.

DUARTE, Constância Lima. Mário de Andrade e as escritoras do seu tempo. In: AYALA, Maria Ignez Novais; DUARTE, Eduardo de Assis (Org.). Múltiplo Mário: ensaios. Natal: EDUFRN, 1997. p. 99-114.

HESS, Elisabeth Ingeburg Souza. Dilema recalcado em reificação aguda: a peregrinação parnasiana entre formação da literatura no Brasil e forma da arte atemporal. Revista de Estudos Literários Água Viva, Brasília, v. 1 n. $1,2009$.

JÚLIA, Francisca. Esphinges. São Paulo: Monteiro Lobato e Cia Editores, 1921

JÚlIA, Francisca. Mármores. São Paulo: H. Belfort Sabino, 1895.

JÚlIA, Francisca. Poesias. São Paulo: Conselho Estadual de Cultura - Comissão de Literatura, 1961.

KONDER, Leandro. As artes da palavra: elementos para uma poética marxista. São Paulo: Boitempo Editorial, 2005.

LEFEBVRE, Henri. O pensamento marxista e a cidade. Tradução de Maria Idalina Furtado. Lisboa: Ulisseia, 1972.

LÔBO, Danilo. Francisca Júlia: entre o pincel e a pena. Florianópolis: Travessia, 1991.

LÔBO, Danilo. Introdução à estética Parnasiana. Brasília: Thesaurus, 1994.

MARTÍNEZ, Alfredo Rosas. Rodolfo Fierro: el "otro" Centauro del Norte (Historia, literatura y mito). Ciencia Ergo Sum, Cidade do México, v. 18, n. 1, 2011. 
MARTINS, Ana Luiza. Revistas em Revista: imprensa e práticas culturais em tempos de República. São Paulo (1890-1922). São Paulo: EDUSP, 2008.

PIRAS, Tiziana. Il mito classico nella letteratura italiana. Dal neoclassicismo al decadentismo. Italian Culture, East Lansing, v, 23, p. 178-181, 2005. 